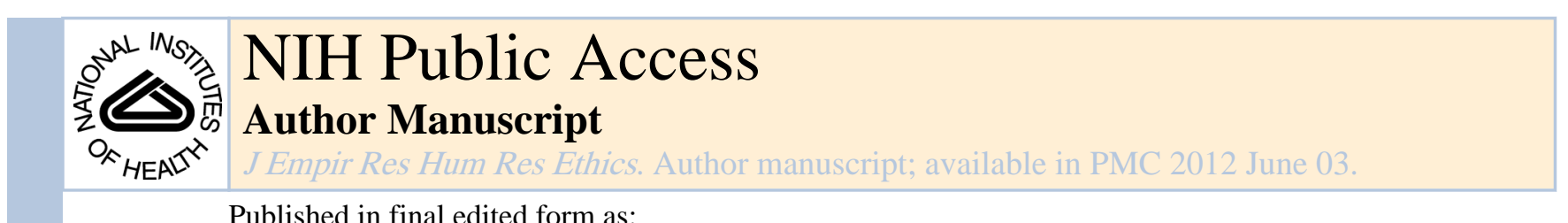

Published in final edited form as:

J Empir Res Hum Res Ethics. 2009 September ; 4(3): 73-87. doi:10.1525/jer.2009.4.3.73.

\title{
Parents' Online Portrayals of Pediatric Treatment and Research Options
}

\author{
Rebecca Schaffer, \\ University of North Carolina at Chapel Hill \\ Gail E. Henderson, \\ University of North Carolina at Chapel Hill \\ Larry R. Churchill, \\ Vanderbilt University Medical Center \\ Nancy M. P. King, \\ Wake Forest University School of Medicine \\ Barbra B. Rothschild, \\ University of North Carolina at Chapel Hill
}

Sara Lohser, and

Cleveland Clinic Foundation

Arlene M. Davis

University of North Carolina at Chapel Hill

\begin{abstract}
Parents of seriously ill children face difficult decisions when standard therapies are limited or ineffective. In their search for information, they may turn to websites created by other parents facing similar experiences. We conducted a qualitative content analysis of 21 websites created by families with children affected by cancer or genetic disease, two serious conditions with a range of treatment and clinical trial options. Our research questions address how parent authors portray serious pediatric illness, available options, parties to decision making, and sources of influence. In addition, we examine what these sites reveal about family vulnerability to various risks, particularly the risk of misunderstanding the distinction between standard treatment and research and the risk of overestimating the likely benefits of research participation, as well as whether vulnerability varies by type of condition. Our results demonstrate typically favorable views on research, but with inadequate distinctions between research and treatment and a complex set of trade-offs in consideration of research risks and potential benefits. While portraits of vulnerability emerge for both parents and children, so do portraits of strength and resilience. As a result, parents describe frustration with both under- and over-protection from research participation. Our discussion of these findings clarifies the potential for parent-authored websites to inform and influence families considering research and treatment options for their seriously ill children.
\end{abstract}

\section{Keywords}

parents; pediatric; online; clinical trials; pediatric oncology; pediatric genetic conditions 
Parents sometimes face difficult decisions about care for their seriously ill children, especially when standard therapies are ineffective and research participation is a consideration. When confronted with decisions, parents increasingly turn to the Internet to supplement, interpret, or challenge the information they receive from health care providers (Christian, Kieffer, \& Leonard, 2001). Sites created by other parents to share first-hand experience of treatment and research options may be especially influential (Schaffer, Kuczynski, \& Skinner, 2008; Skinner \& Schaffer, 2006; Han \& Belcher, 2001) for some parents. Examination of these websites provides an opportunity to understand the experiences of parents and children in crisis, including the world of physicians, researchers, family, and friends who accompany them on this journey. The websites are a window into parents' decision making, perceptions of serious family illness, and their assessments of risks of harm and potential for benefit in both standard treatment and clinical research. Parents motivated to create a website may differ from their readers in important ways; they have strongly felt convictions and a willingness to share them. Yet they may also provide valuable insight into the ways in which families may be vulnerable to various risks in the course of identifying research and treatment options.

While the vulnerability of seriously ill children and their families is well accepted (Rossi, Reynolds, \& Nelson, 2003), the role of websites in understanding the detail and complexity of this vulnerability is underappreciated. Our study provides an important first step in examining these online portraits of serious pediatric illness.

\section{Method}

Our study examined 21 websites created by families with one or more minor children (living or deceased) affected by cancer or genetic disease, two serious conditions with a range of treatment and clinical trial options. We selected these two conditions expecting fewer options generally for children with genetic conditions, compared to those with cancer who are typically offered treatment in the context of research. We conducted a qualitative content analysis of these websites to answer the following research questions:

1. How do parent authors portray serious pediatric illness and the research and treatment options available to them? Do these portrayals differ based on type of condition (cancer vs. genetic illness)?

2. How do parent authors portray decision making about current and future options? Who is involved in these decisions? What sources of information are most influential?

3. What do these sites reveal about family vulnerability to various risks, particularly the risk of misunderstanding the distinction between standard treatment and research, and the risk of overestimating the likely benefits of research participation? Does vulnerability vary by type of condition?

The vivid imagery and content of sites in our sample are illustrated here by summary presentation of two such sites, Alex's Lemonade Stand and Nathan's Battle. Figures 1 and 2 provide screenshots of the home pages of these two parent-authored sites.

Alex's Lemonade Stand is a research-focused site that raises awareness and funding for research on childhood cancer and advocates for increased enrollment of children in clinical trials. Created by the parents of a young girl diagnosed with neuroblastoma at age 1, the site describes their daughter's brave and very public fight against cancer and her success in setting up her own lemonade stands to raise money for cancer research before her death at age 8 . Honored as a heroine and role model, Alex appeared on local and national news 
programs, talk shows, and in newspaper and magazine articles. Her parents and their supporters established the foundation and website that carry on Alex's work.

The bulk of the site is very upbeat with bright primary colors, the lemonade theme song, and inspirational phrases and anecdotes encouraging people to join this cause. Site contents include a gift shop, a direct donation option, information on fundraising events, a page of facts on childhood cancer, a journal that chronicles fundraising and grantmaking efforts, a list of corporate sponsors, the history of the foundation, information on how to set up a lemonade stand or related fundraising effort, links to mass media accounts of the foundation's work, information for children, photographs of both Alex and fundraisers nationwide, and a children's art showcase. A link to the family's personal journal provides a detailed account of the family's efforts to save Alex's life and the difficult choices they faced. (The journal is hosted on another website, www.CaringBridge.org, which assists families in creating free web pages to share information about their children's health with friends and family.) While the primary site presents research as an overwhelmingly positive endeavor, the journal presents a more nuanced picture of the lived reality of participating in clinical trials.

Nathan's Battle is a research-focused site created by the parents of two young boys with Late Infantile Batten Disease. Their father, Phil, launched the web site in 1998 to house all of Nathan's medical records: "Phil spent countless hours researching possible therapies and diagnoses by e-mailing his records across the world. Phil and Tricia realized the importance of being the focal point for all of Nathan's medical records and began the battle to help Nathan." The site evolved to promote clinical trials involving gene transfer research (often called gene therapy) as Nathan and his younger brother PJ participated in one round of gene transfer research. The site documents and promotes this family's efforts to overcome economic and regulatory challenges to their participation in future research. Site contents include information about the disease and related research efforts (the father's summaries and links to media coverage of research funded by the foundation and other research efforts), the boys' story, pictures of the boys, their medical records, and information about fundraising efforts and opportunities to donate funds.

\section{Selection Criteria}

Our first goal was to identify pediatric cancers and genetic disorders best suited to our research questions, and for which clinical trials were underway or discussed as a future possibility. We searched the National Cancer Institute's website (http://www.cancer.gov); a list of conditions identified by the National Human Genome Research Institute with planned gene transfer research trials (http://www.gemcris.od.nih.gov/); two comprehensive NIH online directories (http://www.nci.nih.gov/cancertopics/alphalist/a-d, and http://ghr.nlm.nih.gov/ghr/conditionsByName); databases such as BioMed Central, eMedicine, MEDLINE, PubMed, and OVID; http://clinicaltrials.gov; and websites devoted to specific diseases and disorders. We next conducted extensive Internet searches for parentauthored websites that focused on these identified conditions, using popular search engines such as Google and Yahoo, and search terms that included specific diseases (e.g., Hodgkins, Canavan Leukodystrophy), umbrella terms for related diseases (e.g., "orphan" diseases, "childhood cancer"), and research options (e.g., "gene therapy," "bone marrow transplant"). We also reviewed the websites of children's hospitals, national foundations, and other agencies and organizations designed to reach families affected by serious diseases.

From the resulting pool of 81 sites, we selected websites that varied by family/disease characteristics, experimental and standard treatment options, the child's age, and prognosis -all factors that we expected might be related to our research questions. We included an equal number of sites authored by families affected by childhood cancers and genetic 
diseases. We included some with children old enough to contribute to the site and/or participate in decision making about their health care. We included sites for which the affected child was deceased, in remission or considered cured, or was still undergoing treatment with an unknown prognosis.

Finally, we selected sites that clearly demonstrated the family's desire to share their experiences with the public, evidenced by some combination of the following elements: an explicit statement of desire for a broad audience (e.g., in a mission statement), educational information designed to raise awareness about the disease or specific treatment or research options, links to resources, requests for donations, invitations to sign a guestbook, and requests that visitors spread the word about the site. Parents who author these sites often see it as their duty not only to advocate on their child's behalf but also to share what they have learned with other families, and sometimes to advocate for particular options. For example, the FightSMA website provides an educational program to transform a mother of children affected by this genetic disease into a FighterMom, "a mother turned activist, battling ANY serious or incurable disease or disorder affecting her child."

To further ensure that we included only advocacy-oriented sites, we excluded websites that required a password, visitor registration, knowledge of a specific URL, or some other tool designed to restrict access. Although our study was identified as exempt from IRB review given the public nature of the information reviewed, we added these criteria due to the highly sensitive information contained in some family-authored sites.

Our sample of 21 sites is not representative of all childhood conditions or all parental websites. After systematically surveying pediatric cancer and genetic disease conditions that offered both standard and experimental options, we selected parent-authored websites based on a purposive sampling strategy. We selected sites that would maximize variety along dimensions of interest regarding parental decision making, including disease/condition, available options, child's age, and prognosis. Because we were especially interested in how parents characterized the potential for benefit from research participation, we chose to include more pro-research sites as they were more likely to discuss benefits attributed to clinical trial participation. The sites in our sample that advocated against FDA-approved research options provided rich data on research-related risks. Perhaps most important, we excluded websites that did not meet our criteria for advocacy-oriented sites.

\section{Sample Description}

The final sample includes 11 sites devoted to children with pediatric cancers and 10 sites devoted to children with genetic disorders. The age of the focal children at the time of diagnosis ranged from 1 day to 17 years; the children's age at the time of this analysis (or at death) was 2.5 to 20 years. At the time of the analysis, 8 of the 21 focal children were deceased. The time span covered by the sites ranged from 2 to 10 years, with an average time span of 5 years. Appendix A provides a list of contents included in at least one of the sites. Appendix B provides descriptions of all 21 websites.

\section{Coding and Analysis}

The research team initially reviewed all 21 websites in their entirety, noting portrayals of the condition, family members and roles, decision making, and available treatment or research options. Sites were reviewed again and coded to record an in-depth site description and preliminary interpretations of research and treatment options. The coding form was developed based on our research questions and refined through an iterative process of coding and re-coding several practice websites. It includes these data categories: website; authorship; disease and family information; authors' goals; portrayals of research and 
treatment, including skepticism or enthusiasm about research and distinguishing it from treatment; narrative aspects of the website, including portrayals of child, family members, doctors, and researchers and their related roles; website components such as slogans, metaphors, photographs, links, and appeals for donations; and general impressions of the website, focusing on memorable aspects.

All members of the research team coded two cancer and two genetic disease websites to refine the form and ensure coding consistency. One researcher independently coded the remainder of the sites. A second coder provided a check on four of the remaining sites, and the few discrepancies in coding were discussed during team meetings. A third coder provided a check on items related to technical aspects of clinical trials across all 21 sites. There were no important discrepancies in coding on these items. We created a data summary matrix to compare information (including verbatim quotes from parent authors) within and across sites, test our interpretations of the data, and draw conclusions about the depiction of research and treatment options and related decision making. All such segments were collated and analyzed for cross-cutting themes (Miles \& Huberman, 1994). Regular team meetings allowed for ongoing assessment of the data analysis and of the extent to which the resulting data summary matrix enabled us to address our research questions.

\section{Results}

\section{Portrayals of Condition and Options \\ CHILDHOOD CANCERS-The websites in our study clearly reflect that for most} children with cancer, clinical trials are perceived as the only option other than palliation. Eight of the 11 cancer sites in our sample endorsed mainstream clinical trials as the only hope for a cure, or for prolonging life until a cure is available. These online journals contain references to multiple standard and experimental interventions; to basic research for which they donated tissue samples; to complementary therapies such as nutritional supplements used to mitigate the side effects of treatment and research protocols; and, in cases where the child was near death, to palliative and hospice care. The remaining three cancer sites were less enthusiastic about current research, sometimes critical of the FDA's authority to permit or prohibit certain research options, citing barriers to enrollment in existing trials, or speculating about collusion among governmental agents, industry, and researchers to restrict treatment options. These sites emphasized preventive options such as forgoing vaccinations and avoiding common forms of radiation, and alternative options not approved as "first-line" research or treatment interventions for childhood cancers. Among our 21 sites, only these three cancer sites were skeptical, rather than enthusiastic, about mainstream research.

Portrayals of existing options often do not differentiate standard from experimental or alternative interventions. Terms such as "treatment" and "therapy" were frequently used by both physicians and researchers to describe clinical trials. At Alex's Lemonade Stand and Trinity's Diary, Alex (neuroblastoma) and Trinity (acute lymphocytic leukemia), like some other children in our study, obtained "compassionate release" from the FDA to use experimental treatments outside of clinical trials. Children with very rare cancers (such as those on the website Carly Laverty, created for a girl with mesenchymal chondrosarcoma) were "treated" with protocols modified from different cancers or with FDA-approved protocols tested only in adult populations. Parents were most likely to note the exact nature of such a "treatment" if they had to apply to enter a clinical trial or to petition the FDA to receive it.

Some parents viewed this ambiguity as a sign of medical malfeasance. At Our Alexander, the parents explained that they had been intentionally misinformed about the nature of a treatment that they depicted as forced on their infant son with a brain tumor. The treatment 
was offered as a new, state-of-the-art chemotherapy, but they later discovered that it had a long history of dismal results in previous clinical trials. At Pray for Katie, the Werneckes explained that they had received misinformation about their daughter's options for Hodgkin's Lymphoma. In the course of a resulting lawsuit, Katie's lawyer wrote:

It has recently come to the Werneckes' attention that the treatment regimen the State is presently forcing Katie to undergo is entirely "experimental" in nature. This fact was never explained to the Werneckes. In fact, the prescribed treatments were always referred to as "necessary" and the "only course of treatment available." Actually, the treatment is part of a Stage II clinical trial program ... It is not a proven-effective course of treatment for the treatment of Hodgkin's disease. See http://www.cancer.gov/clinicaltrials/CPG-AHOD00P1.

GENETIC DISORDERS-While fewer options existed for the families affected by genetic disorders in our sample, all ten sites were very enthusiastic about research. Only one site, The Official Alexi Soraya Site, emphasized existing treatments and late-phase clinical trials for the affected children's osteogenia imperfecta. The other nine sites focused primarily on research that might lead to a cure in the future and, in some cases, some benefit for current research subjects. Devoted to Brianna portrayed early-phase gene transfer research (GTR) as the only potential cure for Brianna's Canavan leukodystrophy; and Nathan's Battle portrayed GTR as the only potential cure for Nathan and brother PJ's Late Infantile Batten Disease. At Hope for Henry, the parents of a young child affected with Fanconi's Anemia described how they "pushed the envelope" by pursuing nine rounds of in vitro fertilization with pre-implantation genetic diagnosis (IVF-PGD), hoping to produce a non-affected, genetically matched sibling to allow a second bone marrow transplant for Henry. At the same time, they advocated for and described their collaboration with scientists on international research that might lead to future treatments.

While families affected by genetic disorders typically adopt a future-oriented focus on research and use terms such as "clinical trial" and "translational research" when explaining their decisions, they also blur the boundary between research and treatment by characterizing current research interventions as treatment. For example, Brianna's mother (speaking as Brianna) describes GTR as "the research I'm in to save my life." Nathan's and PJ's parents describe GTR as a potential "life-saving treatment." At Charley's Fund, his mother, after explaining that the current, non-curative treatment options for Duchenne Muscular Dystrophy are extremely limited and entail serious side effects, looks forward in this way:

Because there is so little scientific data on the disease, we have been seeking out doctors who suggest treatments that they "have a hunch" might help based on anecdotal evidence. Although this is a scary basis for medical decisions, we have no choice but to take a chance on [them] until there is more empirical evidence on which we can rely ... [Explaining their focus on future experimental therapies:] "It's so important—and therapeutic—-for us to focus on the potential of the future. So we don't usually go into detail about how Duchenne is affecting Charley every day of his life.

Despite such statements, these parents and others who anticipated future benefits from present genetic research tended to be much clearer than the parents of children with cancer about the differences between research and treatment. These parents were very specific about advocating for research, often discussing a need to streamline the FDA approval process necessary to move laboratory research to human trials, and sometimes on to standard treatment with the larger population of affected children. However, just as with the 
cancer sites, when clinical trials were available, parents tended to blur the research-treatment distinction.

\section{Decision Making for Children with Serious Conditions}

The parents who author these sites chronicle their difficult decisions regarding treatment and research options for their child. The decision making is portrayed as a confusing, unwieldy process of weighing both scientific and experiential knowledge. Parents gather and manage information, seek second opinions and legal counsel, interpret research, monitor their child's signs of deterioration or improvement, and ultimately serve as final arbiter among many voices.

INDIVIDUALS INVOLVED IN DECISION MAKING-As the following examples illustrate, parents, children, physicians, and state and federal officials occupied different and sometimes unexpected roles, varying by site and over time.

On Alex's Lemonade Stand, the focal child occupied the roles of monitor and interpreter of signs/symptoms, along with her parents and doctors, during certain stages of her treatment: "She is so aware of her body that she actually told Dr. Maris last week, after a delay in starting her chemo due to her poor counts, that she needed to start her Temador [chemotherapy agent] to feel better. So, despite her poor counts, we started her on her chemo and of course, it did make her feel better in some ways." Earlier in their quest for treatment, Alex's parents attributed great interpretive power to her oncologists and great respect for her activism:

We came here then thinking we were coming for a one time treatment—something to relieve her pain and give her "more time."... The fact that her cancer was reduced so much by the high dose MIBG [radiotherapy] led to the recommendation by her oncologists to pursue more aggressive treatments. I would not have imagined that four years later our lives would still be so consumed by her hospital visits and her future would still be so uncertain.... I also never would have guessed that Alex would become such a successful activist for childhood cancer.

At Valerie Grace, the parents of a young girl with a rare brain tumor occupy the role of final arbiter. Despite their self-described "anti-medicine" stance, they view the chemotherapy as the way to follow God's word:

Two studies I looked at of pilomyxoid astrocytomas (the only ones I could find) showed more deaths of children who did chemo than children who chose no treatment.... The studies included a very small sample of children, and I know that God does not work off statistics. However, the studies seem to support the choice we are making. [And later] I can't believe we are doing the chemo! We always said noway. But we prayed (and prayed, and are praying) and really hear God saying yes.

Three other sites detailed how the FDA, child protective services, foster parents, the courts, and/or biomedical professionals took over the role of final decision maker when the parents expressed concern about or resistance to the prescribed course of treatment or research intervention (i.e., chemotherapy and/or radiation). Only one of these sites, Pray for Katie, documented a family's success in challenging state intervention in decision making about treatment and research options.

\section{CRITICAL ROLE OF RELATIONSHIPS WITH PHYSICIAN RESEARCHERS-}

Parents who were enthusiastic about biomedicine typically described powerful relationships with physicians and/or researchers. Henry's family depicted an intimate relationship with 
researchers and described a lab in which photos of Henry were hung on the wall by researchers working on "his" cure. In her blog, Charley's mother included a letter she received from a scientist working with her son's tissue samples, suggesting a strong personal commitment to curing Charley's degenerative disease, and the power of a parent-authored website to serve as a catalyst for scientific research:

I took the liberty of checking out the web-page for Charley's Fund and was quite touched by your predicament. I have 2 boys of my own and, given the situation, it struck me quite hard that time is not on our side if we are to help him. I don't care about the funds at this point ... I initiated the project today. I have assigned my best technician to make the gene targeting vector (though we will all pitch in). After I described the problem to him, he was overwhelmed with honor at being asked to pursue such a noble endeavor. I can personally assure you that, of everyone I know, he is the person who can make this vector as fast as is humanly possible. It is a fairly complicated gene modification to make ... Today, I designed the vector and we are on the move ... Anyway, I just wanted to let you know that there will be no more delays. Charley and many other children are too important for me to wait any longer.

In her blog, Alex's mother reveals her faith in her daughter's doctor, who had advised participation in numerous clinical trials over the course of Alex's illness:

Dr. Maris and we have given this a lot of thought and we all feel that she has the potential to benefit from this study, and there is not a high risk to her overall health (although there is obviously some degree of unknown and known risks in any study) ... Dr. Maris has always taken the "big picture" into account when treating Alex and we know that he would not recommend switching her to something that he did not feel had real potential to benefit her.

Thus, while these parents typically conducted their own research and attempted to find support for their doctors' recommendations, they were often persuaded to consider specific options in the context of trusting relationships with physician and/or researchers.

On the other hand, families who lacked these close ties to and great trust in biomedical professionals, either due to general skepticism or past experiences, tended to seek second opinions and/or challenge the recommendations made by their child's physician. Based in part on their negative experiences with specialists, hospitals, and Texas Child Protective Services, Katie's parents resorted to the court system to fight their oncologists' recommendations. Daniella Rogers's father stated that while he initially believed that his daughter would get the best possible care for her rhabdomyosarcoma within a clinical trial, he later learned that the doctors had misled him by equating it to the best standard care available. Once he became aware of their errors, he identified hospitals that provided different treatment and research options and asked to move Daniella to one of them, but it was too late. He believed that her doctors failed to report negative outcomes in their research; did not monitor his daughter for signs of known, potentially fatal side effects; failed to diagnose the disease that finally killed her; and then changed her medical records to cover their tracks. He wrote:

Our mission in life is to help parents of children, and anyone who takes part in research.... There are millions of more dollars dedicated to the recruitment of children into research than with anyone else. We want parents to know that they do have choices in their child's treatment. We hope you will take the time to look over [this] site and educate yourself.... Please be aware that when you take your child to a teaching hospital you will need to educate yourself on which treatments are 
"standard of care," and which ones are not. Need help deciding? Please email us with your concerns.

\section{Portrayal of Risks and Benefits of Options}

HOW INFORMATION IS PORTRAYED—The sites in our sample offer an extraordinary

variety of source materials on risks and benefits, including what parents learned from conversations with physicians or other parents, the parents' online research, their observations of how their children reacted to various options, and quotes from children about how an option makes them feel or their hopes for a future option. Parents provide many links to other information, such as research articles; websites for hospitals, individual physicians/researchers, foundations, and support groups; and mass media reports on research advances or exposés. For some sites, home pages and fundraising pages focus solely or primarily on potential benefits, and information on risk is buried in the narratives contained in personal journal pages. Other sites have entire pages devoted to risks and benefits, with consent forms, clinical trials information, and copies of physicians' notes and medical records.

All sites include information on the benefits of at least some of the standard and experimental options they discussed. The range of anticipated benefits included curing the child, prolonging the child's life, reducing pain/discomfort or specific symptoms, improving the child's (and the family's) quality of life, and improving treatment options for all/future children. Benefits were sometimes discussed with great specificity (e.g., expected reduction in tumor size), while at other times they were vague (e.g., "keeping hope alive"). "No change" is explained as a benefit as Nathan's family describes their research experience:

Nathan goes to NYC to have his 6 month evaluation performed. This evaluation includes a MRI and MRS [medical imaging and measures of metabolites] to better help evaluate the effects of the treatment.... Nathan's MRI shows No Change! Again, given the goals of the treatment to stop the progression of the disease, no change is a POSITIVE result, meaning if the brain doesn't show more degradation then the therapy may be working.

While all of the childhood cancer sites included risk information, only two of the genetic sites did so. This split corresponded to differences in the availability or immediacy of the option under consideration. Risks of harm were broad in scope: pain, suffering, or debilitation during the course of treatment or trial participation; possible ineligibility for future trials; burdens on siblings, parents, and other family members; and long-term effects, such as risks of later cancers attributed to current treatment. As Valerie Grace's mother reflects on the decisions made to treat their daughter's rare brain tumor, she imparts lessons her family has learned about social harms, such as harsh judgments by others for their decisions:

We have learned a lot this year, but I have been tested in big ways over the past few months when it comes to relationships. In part, from being isolated and feeling lonely at times-in part from hearing from people that we are making the wrong decisions/or that we waited too long to start the chemo. But I know that we have done things just as God has called us to, and truly have no regrets (other than the way I feel when I hear such things).

\section{AUTHORS' REASONS FOR PRESENTING RISK AND BENEFIT INFORMATION -Parents provide risk and benefit information for a variety of reasons. Some, for example, do so specifically to educate website visitors seeking information about available options or to encourage financial support either for related research or for their child. Others include this information in the course of explaining the decisions they have made or in critiquing}


decisions made for them by doctors, state agencies, and others. In two of the three skeptic sites, parents offered copies of both "bad" consent forms that had misled them and "good" consent forms, obtained from other sources, that the parents felt offered better descriptions of risks and benefits. They also included graphic descriptions of the negative outcomes of certain "treatments," which they felt should have been emphasized as likely risks of that option.

Detailed family sagas may accompany descriptions of benefits sought. Nathan's parents describe their fight to obtain GTR for their two sons with a timeline of events and entries dealing specifically with the potential benefits of GTR for their sons. They link observed outcomes in laboratory mice to potential outcomes in humans ("it will work"), and they describe the positive outcomes of their sons' involvement in research as reasons to push the FDA to move faster in approving new clinical trials involving humans. Likewise, Brianna's mother uses several types of benefit information in her appeal for inclusion in GTR clinical trials for her daughter's degenerative genetic condition:

Gene therapy has grown in the past year. Our first treatment was a Liposomal Vector injected through a shunt in the top of the head, and only penetrated what it hit. Now, with all the new technology, our next treatment, which is currently awaiting FDA approval, is going to be a Viral Vector, which is to be a thousand times stronger than the first one. With this, the doctors are going to drill 6 tiny little holes at the pin point areas of the brain and through that they will inject the new gene. It has been said that with the proper therapy and rehabilitation afterward they do not see why they would not be walking. Of course this is experimental and that is not a definite but it is a bigger hope for those families involved. Brianna's first treatment was done in March of 1998. Before the operation she was considered legally blind, glasses would not help. She had very little head control and her muscles were very tight. Since the operation she has had no further deterioration in the white matter of the brain, which is what this disease affects. She has glasses now and can see $4-5$ feet in front of her. She can lay on her stomach and lift her head up, she is not tight fisted any more, and is much happier, it seems. I feel that if the first treatment can do all this, just picture what the next one will do.

COMPLEX TRADE-OFFS-Parents depict complex trade-offs among a broad array of potential benefits, risks, and burdens with striking regularity. Some caution about the tradeoffs between the short and long-term effects of their choices. Joshua's mother, for example, wrote at Joshua's Journal regarding her son's Ewing's Sarcoma:

Now, our options [after relapse] are not good ones as we have to accept the fact that we have to do everything possible to stop this monster, which could mean some long-term side effects that we hoped not to have to face.... I pray he will understand as much as possible at his young age that we have no choice right now.

Similarly, Alex's parents view each round of chemotherapy leaving Alex weaker than the last, as a desperate cycle, until she will no longer be eligible for particularly promising clinical trials should they arrive during her lifetime. Focused on the short-term benefits she observes, Brianna's mother fights for repeated participation in GTR, until doctors tell her that Brianna is no longer likely to benefit from them due to advanced brain deterioration.

Paradoxically, a child's current good health may complicate decisions, as the same signs of "good health" can hold opposite meanings for families with different goals. Alex's mother stated that the stronger Alex was going into a study, the better she was likely to do. In contrast, Katie's family wanted to stop tumor growth with minimal medical intervention. Her parents decided that when Katie was in good health, they would choose not to try 
anything new. In his blog, Henry's father covers the gamut of difficult issues raised in many sites:

Though everyone in the family is itching to go home, I am worried about leaving too soon.... I really want those few good weeks of nutrition, no pain, stable counts, but laurie, understandably, doesn't believe that is going to happen any time soon and thinks henry will be better off at home. Sometimes I think she is the champion of "quality" of life, while I stick crazily to this notion of "quantity" of life. But it really isn't that simple. I think that we often get to the point where we've had just too much of the hospital and all of the associated dehumanizing nonsense and get greedy for home. And we think that the more we're away the harder it is for henry to get better because his emotional well-being has such a strong connection to his physical recovery. But often we rush home only to turn back around a day or a week or a month later for the hospital.

Henry's mother, Laurie, also reflected on quality-of-life issues, including concerns about the long-term side effects of standard and experimental options and the IVF-PGD:

More than 175 shots, 97 eggs and four potential, but failed, pregnancies later, we were really no closer to saving Henry's life than we were 18 months ago when we took our first step down this path. We could now officially say that we had done everything we could to help Henry. But that was little solace. We wanted to save his life.

\section{Discussion}

In the websites they create, parents of seriously ill children portray the experience of serious pediatric illness, treatment, and research with extraordinary depth. They demonstrate that decisions about treatment and research are complex and deeply embedded social processes, involving an extended network of influences often not obvious to the health professionals caring for sick children or government regulators who oversee their research participation. They reveal a remarkably broad sweep of actors, including parties as diverse as the child, other parents, alternative medicine websites, the FDA, child protective services, and the court system. The sites describe ongoing dialogues between parents and numerous medical professionals and scientists. At times, it is the ill child's embodied experience of the disease that influences a decision; at other times, remote governmental forces intervene, forcing or barring participation in a particular treatment option.

The websites also reveal the multi-dimensional nature of vulnerability for those coping with serious childhood illness. Parents are vulnerable both to misunderstanding the distinction between research and treatment and to misunderstanding and overestimating the potential of medical research to benefit their children. While the goal of treatment is benefit for an individual patient, the goal of research is production of knowledge that contributes to future patient care, regardless of whether or not subjects in a clinical trial benefit from the study intervention or from other aspects of their participation. The tendency to misunderstand the distinction between research and treatment, a phenomenon called "therapeutic misconception," has been observed in many studies (Appelbaum, Roth, \& Lidz, 1982; Daugherty et al., 1995; Joffe 2001; Henderson et al., 2006; Henderson et al., 2007).

Careful attention to the distinction between treatment and research is particularly important in pediatric trials for two reasons. Federal research regulations (U.S. Department of Health and Human Services, 2005) identify children, by definition, as a vulnerable population in need of special protection from the potential risks of research. Risk and benefit in pediatric research are framed differently than in adult research, requiring clearer proof of benefit in relationship to anticipated harms. As a result, children have been excluded from 
participation in very risky research with little or no prospect of medical benefit. The parent authors of three cancer sites-Our Alexander, Pray for Katie, and Daniella Rogers-vividly portray the risks of research participation; such sites may offer evidence of the need for these higher standards and for children's exclusion from clinical trials in which potential risks outweigh benefits.

At the same time, some view this higher threshold of protection as a detriment, preventing the advances in pediatric care they associate with cutting-edge or very risky research. The anguish conveyed by the parents of Brianna, Nathan, Charley, and others attest to these concerns. Such pediatric research has strong support in Team Mat and FightSMA, as in the financially successful Alex's Lemonade Stand. Motivated to act in the best interests of their children, these parents often see research participation itself as a benefit. Physician researchers are also motivated by beneficence to offer-and, as illustrated in Charley's Fund and Hope for Henry, even to develop-experimental interventions.

Thus, strong tensions emerge when choices for seriously ill children seem both few and dangerous. Parents claim vulnerability both when they are not protected enough from zealous researchers or from misunderstanding the likely results of research participation and when their children are excluded from clinical trials that they believe might prove beneficial. We found that both forms of vulnerability were factors across both cancer and genetics sites. Pediatric cancer websites tended to present research as a treatment option. The anger and disillusionment resulting from research participation on some of these websites (e.g., Daniella Rogers) demonstrates that some parents were all too aware of their vulnerability to therapeutic misconception. At the same time, cancer sites such as Alex's Lemonade Stand focused on the vulnerability to reduced options due to a lack of financial investment in pediatric trials. The genetics sites, with few treatment options, more clearly depicted the context of research and expressed hope that future studies might include or benefit their children. However, when clinical trials were currently available for these children, parents described them as treatment options in the same ways observed among the cancer sites. Moreover, their focus on future research highlighted their vulnerability to a lack of options, hence their fight to hasten FDA approval of experimental options.

Parent-authored websites have additional messages about vulnerability for their readers. Sites such as FighterMom focus on vulnerability related to lack of understanding, assuming that knowledge is power. Parents want to help people become powerful by offering both information about treatment options and their risks and benefits, as well as descriptions of their own extensive research and networking with others. For the 14 research-focused fundraising sites such as Alex's Lemonade Stand and Nathan's Battle, vulnerability results from a lack of financial support, either for research generally or for a particular child's participation in research. Parents also endure an everyday vulnerability that has little to do with specialized knowledge or research support. Instead, this vulnerability concerns a set of wrenching tradeoffs. Parents look for hope, for more options, and for a quality of life; they chronicle these related odysseys in detail. At the same time, they are cautious about the range of personal, family, and medical risks that are attached to their quests. These risks are often poignantly illustrated in journal entries, such as those by the parents of Alex and Henry. We found that parents may feel more vulnerable to influences when their child's view of ongoing treatment or research participation differs from their own or those of their doctors, as well as when they lacked strong relationships with clinicians and researchers. Vulnerability, then, was a matter of perspective, based on the particular lived experiences of illness, medical care, and research.

The Internet offers revolutionary opportunities for information-sharing and advocacy such that parent-authored websites may transform family decision making into a public activity 
with the potential to influence the decisions of other vulnerable families worldwide. Advocacy-oriented sites such as those in our sample are particularly useful cases for understanding the processes involved in parental decision making and the sources of their vulnerability. These sites provide extensive information on research and treatment options. They tend to use highly persuasive language and imagery that was intended to be influential for parent visitors. Lastly, because of their links to major gateways, inclusion in search indexes, and frequent coverage in the mass media, parental sites with explicit outreach missions are likely stops for parents seeking information and/or support online.

The importance and influence of parent-authored sites is underappreciated by clinicians and researchers. In contrast to sites created by institutions or professional organizations, these sites provide a rich portrait of the lived experience of decision making and choices for families with seriously ill children. These sites offer insights into the sources of influence on families with seriously ill children, and how these influences affect decision making. They also demonstrate how easy it is to underestimate parental resourcefulness and sources of strength, showing us that at times, vulnerability is a reductive and misleading label. Finally, and perhaps most importantly, these sites are written by, and intended to help, people of varying backgrounds and skills, reaching across class and educational barriers. We must not fail to appreciate the influence that parent sites may have on other families faced with similarly difficult, important, and tragic choices.

\section{Best Practices}

In offering treatment or research participation to parents of seriously ill children, it is often important to understand the sources of information parents find helpful for their decision making. While researchers and clinicians may view parent-authored websites as potentially misleading sources of medical information, they should consider more than the accuracy of the medical information in their assessment. These sites are also powerful sources of information on perceptions of parental roles, on how and where parents should seek information, and on similarities or differences between research participation and treatment. Rather than dismiss parent-authored sites, researchers and clinicians should ask parents where they have sought information and what they found useful. Such an assessment may help researchers and clinicians bridge potential gaps in understanding treatment or research options, in aligning goals in the child's best interests, and in respecting the preferences and values of the family. An understanding of these influences may help researchers and clinicians address the complex concerns and needs raised by this illness experience.

\section{Research Agenda}

Little if any research has described the content of parent-authored websites as we have in this paper. Still less has focused on the impact of such websites on families who are seeking help in making decisions about their seriously ill children. We need a better understanding of this growing phenomenon. And because these sites sometimes share a relationship with websites such as CaringBridge, which aim to offer families a protected web space to share communications regarding ill family members, their goals and expectations of privacy should also be examined. Finally, because we restricted our sample to those websites with an explicit advocacy agenda, there are many sites—possibly quite influential—that were excluded from our analysis. A more systematic sample of all such websites is an important next step for research that examines influences on parents making decisions. Such an exploration may provide valuable teaching tools for future clinical researchers and provide insight to government agencies conducting studies or regulating products about how to better communicate with parents and be transparent about conduct and oversight of clinical trials. Of particular interest may be the close relationship between some families and the 
researchers that may undermine scientific independence and voluntary participation in clinical research. To give just one example, the NIH Recombinant DNA Advisory Committee raised concerns about the research in which Nathan and his brother were enrolled, after some subjects died. As a result, the principal investigator wrote an article addressing the challenges of conducting research funded by patient advocacy groups, including the need to avoid both undue pressure on investigators and institutions, and the therapeutic misconception. (Arkin et al., 2005)

\section{Educational Implications}

Our results have implications for clinicians, researchers, and IRB members who should become familiar with parent-authored websites as a tool for parent communication and education. For clinicians, because the web content is highly accessible to families from different educational and cultural backgrounds, it offers examples of how families experience serious childhood illnesses and their perceptions of parental and child roles. For researchers and IRB members, website content often advocates for (or more rarely, against) research participation. Thus, their portrayal of research goals or the guidance they offer families is instructive in both reviewing research protocols and in informed consent discussions with families. For everyone, the multifaceted nature of vulnerability portrayed in the websites teaches us about the resourcefulness and complex concerns of families faced with serious illness.

\section{Acknowledgments}

We thank Amber Raynor for her contributions during the earliest phase of the project and Michele Easter for her contributions at the end. Sara Lohser's involvement was supported by the Doris Duke Clinical Research Fellowship Program. The study received support from the Social Construction of Benefit in Gene Transfer Research grant, R01 HG02087, and from the UNC Center for Genomics and Society, P50 HG004488.

\section{APPENDIX A}

Website Contents.




- Medical term glossary

- Information about other affected children

- $\quad$ Explicit advice about standard and experimental treatment

- FDA information/laws/regulations/informed consent documents/legal testimony regarding options and parents' rights

\section{APPENDIX B}

Descriptions of the 21 Websites.

\begin{tabular}{|c|c|c|}
\hline Site Name & Diagnosis and Age & Function/Mission of Site \\
\hline \multicolumn{3}{|l|}{ Cancer Sites } \\
\hline Our Alexander & $\begin{array}{l}\text { Diagnosed at age } 2 \text { with a } \\
\text { brain tumor; died at age 2-1/2 }\end{array}$ & $\begin{array}{l}\text { Informational site set up to memorialize son who died } \\
\text { while on a court-mandated chemotherapy protocol and } \\
\text { to warn other families about the dangers of "standard" } \\
\text { treatments, including vaccinations and FDA-approved } \\
\text { chemotherapies. They hoped to change federal policies } \\
\text { to increase parental control over their children's health } \\
\text { care; to decrease the power of dishonest, profit-driven } \\
\text { researchers and medical establishments; and to advocate } \\
\text { for informed consent and alternative treatments. }\end{array}$ \\
\hline
\end{tabular}

Daniella Rogers

Diagnosed at age 1 with Rhabdomyosarcoma; died at age 5

Pray for Katie

Alex's Lemonade Stand

Trinity's Diary

Carly Laverty

Caleb's Cancer Pages

Joshua's Journal
Diagnosed at age 13 with 14

Diagnosed at age 1 with Neuroblastoma; died at age 8

Diagnosed at age 2 with Acute Lymphocytic Leukemia; died at age 3

Diagnosed at age 4 with Mesenchymal Chondrosarcoma; now age 7

Diagnosed at age 10 months with Hepatoblastoma; died at age 2

Diagnosed at age 1 with Wilm's Tumor; now age 11

Diagnosed at age 4 with Ewing's Sarcoma; now age 8 Hodgkins Disease; now age
Informational site set up after daughter died to warn families about the dangers of FDA-approved clinical research. They advocate for informed consent and hope to raise awareness about this type of cancer and the full range of treatment and research options.

Informational blog set up to promote prayer for Katie and to share updates on Katie's health with family and friends. The blog evolved into an advocacy site through which her father, mother, and Katie herself raised awareness about their battle against "state-sponsored medical terrorism." They also sought financial, legal, and medical assistance from their readership.

Research-focused site set up to raise awareness about and funding for pediatric oncology research. Through their foundation, Alex and her parents advocated for child enrollment in research and provided grants to support pediatric clinical trials. The site also includes a link to the family's CaringBridge journal.

Fundraising site set up to raise money to cover their own health care costs and then, after her death, as a trust fund to provide palliative and hospice care, and to support AML families in financial crisis. The site also contained informational updates for family and friends; detailed information about complementary nutrition, palliation, and hospice services; and a memorial to Trinity.

Informational website set up to provide updates for family and friends; to raise awareness about the disease to advocate for research and treatment funding; and to raise money to support families of children with serious illnesses.

Informational site set up to provide updates for family and friends; to share information with other affected families; to raise awareness about this type of cancer; and to share information about fundraisers that support research.

Informational site set up to share updates with friends and family, and to advocate for pediatric research.

Informational site set up to share updates with friends and family. It contains a link to an affiliated support- 
Site Name

Valerie Grace

Genetic Sites

Devoted to Brianna

Charley's Fund

Hope for Henry

Bethany's Hope

The Official Alexi

Soraya Site

Rachaeli

Nathan's Battle

Adriana van Merwe

Team Mat

Diagnosed at age 2 with Cystic Fibrosis; age 11 at analysis with Pilomyxoid

Astrocytoma of the optic now age $2-1 / 2$

Diagnosed at age 17 with died at age 19 with Canavan's analysis

Diagnosed at age 3 with Duchenne Muscular

Diagnosed at birth with age 7

Diagnosed at age 2 with

Metachromatic

Leukodystrophy

Diagnosed at birth with

$3-1 / 2$ at analysis

Diagnosed at age 4 with analysis

Diagnosed at age 5 with SCID; died at age 7
Function/Mission of Site

focused foundation site that provides information and referrals; information management tools; social support/ networking among affected families; and opportunities to raise funds for CureSearch research/advocacy.

Diagnosed at age 10 months chiasm/hypothalamic area Myelodysplastic Syndrome;

Diagnosed at age 9 month

Leukodystrophy; age 11 at

Dystrophy; age 4 at analysis Fanconi's Anemia; died at

Neuroblastoma; died at age 7

Osteogenesis Imperfecta; age

Diagnosed at age 1 with Tay Sachs; age $3-1 / 2$ at analysis Batten's Disease; age 10 at
Informational site set up to share their experiences and research with other families, and to share information about existing and planned research studies.

Information and support-focused foundation site set up to raise awareness about cancer and issues facing teens with cancer; to advocate for research and support services; to raise funds online support services and oncology research; and to memorialize their daughter.

Informational site set up to update family, friends, and larger online community about her status and needs; to raise funds to cover her health care and to support research; to advocate for research funding and access to clinical trials; and to raise awareness about the disease and the need for a cure.

Research-focused foundation site set up to raise funds for translational research, specifically GTR, and to raise awareness and share information about the disease, their experiences, and the need for research.

Support-focused foundation site set up to raise funds for electronic gifts to promote comfort and recovery; to raise awareness about the disease and the need for research funding; to advocate for bone marrow registration and research; and as a tribute to Henry. Parents have two affiliated blogs to chronicle their experiences.

Research-focused foundation site set up to raise awareness about the disease; to advocate and raise funding for research; to share her story to inspire others; and to build community among affected families.

Informational site set up to provide guidance about caring for affected children (for both parents and MDs); to advocate for parent-doctor partnerships in caring for these children; and to update family and friends about the children's progress.

Tribute/memorial site set up to honor daughter; to update family and friends about her status; to provide a therapeutic outlet for Rachaeli's father; and to share information about the disease, related research, and the need to raise funding for research.

Research-focused foundation site set up to raise funding for translational research, especially GTR; to provide information about the disease and related research; to update family and friends; and to advocate for access to clinical trials.

Fundraising site set up to help her family cover her health care costs; to share information about the condition, treatment, and need for research funding and bone marrow donors; and to update family and friends on her status.

Research-focused fundraising site set up to raise awareness about fundraising efforts; to share their son's story; to raise awareness about the disease and the need for research; and to explain technical information related to the disease. 


\begin{tabular}{lll}
\hline Site Name & Diagnosis and Age & Function/Mission of Site \\
\hline FightSMA & $\begin{array}{l}\text { Diagnosed at age 1 with } \\
\text { Spinal Muscular Atrophy; } \\
\text { age 20 at analysis }\end{array}$ & $\begin{array}{l}\text { Research-focused foundation site set up to raise } \\
\text { awareness about the disease; to advocate for research } \\
\text { and treatment; to build a community among affected } \\
\text { families; and to share information about current and } \\
\text { future research. Includes Fighter Mom, the resource } \\
\text { program designed to transform parents into advocates. }\end{array}$ \\
& & \\
&
\end{tabular}

\section{References}

Appelbaum PS, Roth LH, Lidz C. The therapeutic misconception: Informed consent in psychiatric research. International Journal of Law and Psychiatry. 1982; 5(3-4):319-329. [PubMed: 6135666]

Arkin LM, Sondhi D, Worgall S, Suh LHK, Hackett NR, Kaminsky SM, et al. Confronting the issues of therapeutic misconception, enrollment decisions, and personal motives in genetic medicine-based clinical research studies for fatal disorders. Human Gene Therapy. 2005; 16(9):1028-1036. [PubMed: 16149901]

Christian SM, Kieffer SA, Leonard NJ. Medical genetics and patient use of the Internet. Clinical Genetics. 2001; 60(3):232-236. [PubMed: 11595026]

Daugherty C, Ratain MJ, Grochowski E, Stocking C, Kodish E, Mick R, Siegler M. Perceptions of cancer patients and their physicians involved in phase I trials. Journal of Clinical Oncology. 1995; 13(5):1062-1072. [PubMed: 7738612]

Han H, Belcher AE. Computer-mediated support group use among parents of children with cancer-an exploratory study. Computers in Nursing. 2001; 19(1):27-33. [PubMed: 11210451]

Henderson GE, Churchill LR, Davis AM, Easter MM, Grady C, Joffe S, Kass N, King NMP, et al. Clinical trials and medical care: defining the therapeutic misconception. PLoS Medicine. 2007; 4(11):e324. [PubMed: 18044980]

Henderson GE, Easter MM, Zimmer C, King NMP, Davis AM, Rothschild BB, Churchill LR, Wilfond BS, Nelson DK. Therapeutic misconception in early phase gene transfer trials. Social Science \& Medicine. 2006; 62(1):239-253. [PubMed: 16000230]

Joffe S, Cook EF, Cleary PD, Clark JW, Weeks JC. Quality of informed consent in cancer clinical trials: a cross- sectional survey. Lancet. 2001; 358(9295):1772-1777. [PubMed: 11734235]

Miles, MB.; Huberman, AM. Qualitative Data Analysis: An Expanded Sourcebook. 2. Thousand Oaks, CA: Sage; 1994.

Rossi WC, Reynolds W, Nelson RM. Child assent and parental permission in pediatric research. Theoretical Medicine and Bioethics. 2003; 24(2):131-148. [PubMed: 12943268]

Schaffer R, Kuczynski K, Skinner D. Producing genetic knowledge and citizenship through the Internet: Mothers, pediatric genetics, and cybermedicine. Sociology of Health and Illness. 2008; 30(1):145-159. [PubMed: 18254838]

Skinner D, Schaffer R. Families and genetic diagnoses in the genomic and Internet age. Infants \& Young Children: An Interdisciplinary Journal of Special Care. 2006; 19(1):16-24.

U.S. Department of Health and Human Services. Code of Federal Regulations, Title 45 (Public Welfare), Part 46 (Protection of Human Subjects), Subpart D: Additional Protections for Children Involved as Subjects in Research. 2005. Retrieved November 1, 2008 from http://www.hhs.gov/ohrp/humansubjects/guidance/45cfr46.htm\#subpartd

\section{Biographies}

Rebecca Schaffer is a doctoral student in Anthropology at UNC-CH. Her dissertation work focuses on social identities and the development of political consciousness among children in elementary school classrooms. Her other research focuses on the social production of genetic knowledge and has been published in Sociology of Health and Illness, and Infants \& Young Children. 
Gail E. Henderson, Ph.D., is Professor of Social Medicine at the University of North Carolina School of Medicine, Director of the UNC Center for Genomics and Society, and Director of the research ethics core at The North Carolina Translational and Clinical Sciences (TraCS) Institute. A medical sociologist, she has studied perceptions of genetic research in the context of clinical trials, genetic epidemiology studies, and genetic registries. She is co-editor of The Social Medicine Reader (2nd ed., Duke University Press, 2005) and Beyond Regulations: Ethics in Human Subjects Research (UNC Press, 1999).

Larry R. Churchill, Ph.D., is currently the Ann Geddes Stahlman Professor of Medical Ethics at Vanderbilt. His published work deals with several aspects of the ethics of human subjects research, including tensions in the physician-investigator dual role, problems of informed consent, the "therapeutic misconception," and the ethics of gene transfer research. Churchill is an elected member of the Institute of Medicine, National Academy of Sciences.

Nancy M. P. King, J.D., is Professor of Social Sciences and Health Policy at the Wake Forest University School of Medicine and Director of the Program in Bioethics, Health, and Society. She has worked extensively on issues related to informed consent in health care and research, medical decisions at the beginning and end of life, and the development and use of experimental technologies. Her current work addresses benefit and uncertainty in human subjects research and ethical issues in large-scale genetic research and biobanking. She is co-editor of The Social Medicine Reader (2nd ed., Duke University Press, 2005) and Beyond Regulations: Ethics in Human Subjects Research (UNC Press, 1999). She has served on hospital ethics committees, IRBs, and DSMBs, and has taught research ethics in national and international settings.

Barbra Bluestone Rothschild, M.D., Adjunct Assistant Professor of Social Medicine at the University of North Carolina School of Medicine, is an internist with a research interest in human subjects research ethics and in community engagement. Her research has included a grant to examine the decision-making processes of parents considering experimental maternal-fetal surgery after a diagnosis of Spina Bifida, investigation of ethical issues in early-phase clinical trial research, and a study of the concept of ownership of biologic samples collected for research. She has taught clinical and research ethics to medical students and clinical research professionals.

Sara Lohser, M.D., a resident in the Department of Dermatology at the Cleveland Clinic, helped author the paper while a Doris Duke Clinical Research Fellow at University of North Carolina at Chapel Hill. Sara is currently completing her intern year in pediatrics. She has always had a strong interest in patients diagnosed with terminal illness and the manner in which they and their families cope and describe their experiences. Prior to entering medical school, she spent many years working directly with patients and families as a volunteer in children's hospitals and rehabilitation facilities.

Arlene M. Davis, J.D., is Assistant Professor of Social Medicine at the University of North Carolina School of Medicine. With a background in pediatric nursing, law, and bioethics, she is the Director of Clinical Ethics Consultation and Education for UNC Hospitals. Davis is also a member of the research ethics core at The North Carolina Translational and Clinical Sciences (TraCS) Institute. Through the UNC Center for Genomics and Society where she is an investigator, her current research focuses on ethical and legal issues associated with genomic research and the creation of genetic information, especially as they relate to identified vulnerable populations. 


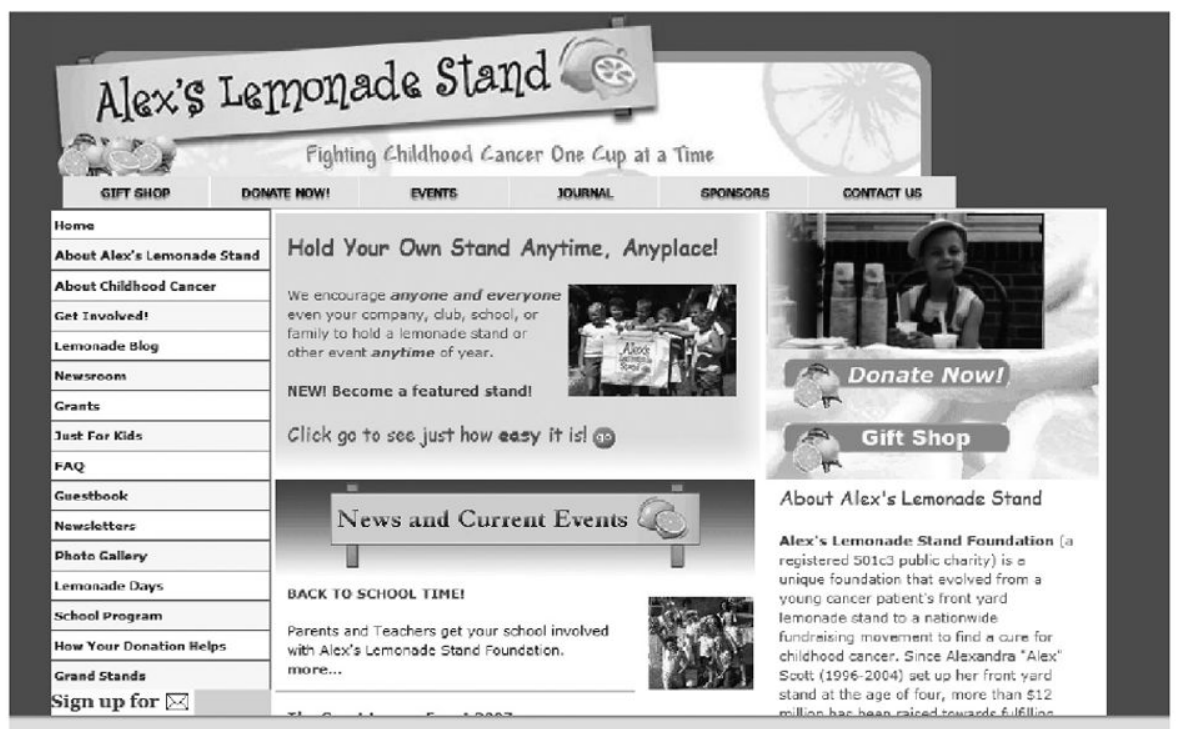

FIG. 1.

Screenshot of Alex's Lemonade Stand's home page, September 10, 2007 (http://www.alexslemonade.org/home). Copyright @ Alex’s Lemonade Foundation. 


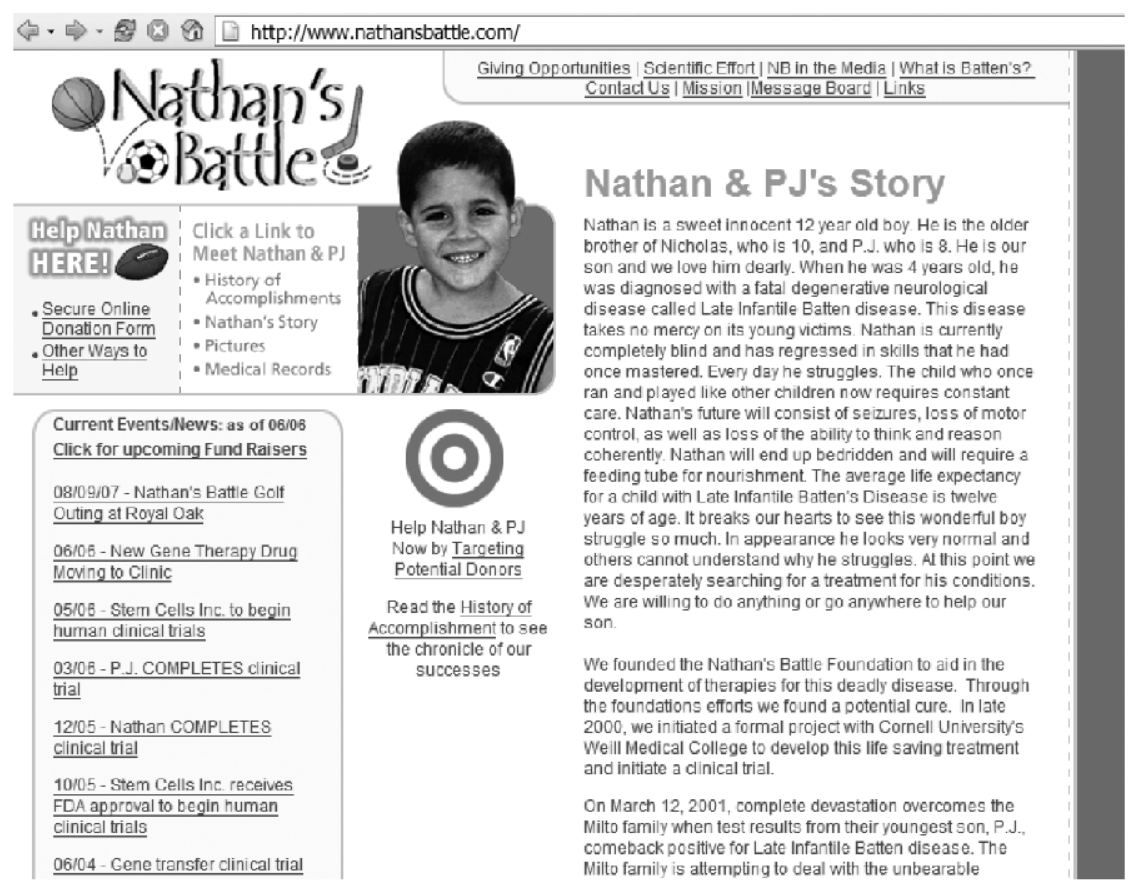

FIG. 2.

Screenshot of Nathan's Battle's home page, September 10, 2007

(http://www.nathansbattle.com/). Copyright @ Nathan's Battle Foundation. 